\title{
PROYECTO BIODAMAZ, PERÚ - FINLANDIA: AVANCES EN LA CONSERVACIÓN DE LA DIVERSIDAD BIOLÓGICA DE LA AMAZONÍA PERUANA Y LECCIONES APRENDIDAS EN LA EJECUCIÓN DEL PROYECTO
}

\author{
Hernán Tello Fernández ${ }^{1}$ y Sanna-Kaisa Juvonen²
}

\section{RESUMEN}

El ambiente está deteriorándose rápidamente en todo el mundo, incluyendo áreas que se pensaba eran remotas, como la Amazonía peruana. El deterioro continuo ha conducido a una serie de convenios internacionales como el Convenio sobre la Diversidad Biológica, para disminuir y mitigar problemas ambientales, proteger derechos de las comunidades tradicionales e indígenas, y conservar la biodiversidad de flora y fauna, incluyendo ecosistemas y genes. La Amazonía peruana es especialmente vulnerable, ya que es un mosaico de diferentes ecosistemas asociados con los Andes, que se manifiesta en una gran variabilidad biológica y física, que a su vez forma la base para su rica diversidad cultural. Esta megadiversidad está amenazada por los patrones de uso no sostenible de la tierra y los recursos naturales, y por la débil institucionalidad respecto a la gestión de la diversidad biológica. En este contexto se inició el proyecto Diversidad Biológica de la Amazonía Peruana, Perú - Finlandia (BIODAMAZ), que es un proyecto de cooperación entre los gobiernos del Perú y de Finlandia (Fase I 1999 2002, Fase II 2003 - 2007). El proyecto BIODAMAZ ha contribuido significativamente a la conservación y uso sostenible de la diversidad biológica a través del desarrollo de herramientas de gestión y metodologías de investigación de la diversidad biológica, logrando los siguientes resultados: fortalecimiento de la gestión ambiental; mejoramiento del acceso a fuentes internacionales de financiamiento en conservación y uso sostenible de la diversidad biológica; mejoramiento de la capacidad de negociación internacional de las autoridades ambientales peruanas; mejoramiento de la sistematización, organización y acceso de información sobre diversidad biológica; fortalecimiento del proceso de Zonificación Ecológica Económica; mejoramiento del conocimiento sobre patrones de distribución de la diversidad biológica amazónica para la planificación del uso de la tierra; fortalecimiento de capacidades locales, regionales y nacionales; y fortalecimiento de la colaboración interinstitucional.

Palabras clave: Amazonía peruana, conservación, cooperación peruano - finlandesa, diversidad biológica, herramientas de gestión, metodologías de investigación, proyecto BIODAMAZ, uso sostenible.

\footnotetext{
ABSTRACT

The environment is rapidly deteriorating across the world, even in areas once thought to be remote, among these the Peruvian Amazon. This ongoing deterioration has led to the drafting of a series of international agreements and conventions, such as the Convention on Biological Diversity, in order to diminish and mitigate environmental problems, to protect the rights of traditional and indigenous communities, and to protect flora and fauna, ecosystems and genes. The Peruvian Amazon is especially vulnerable as it is a mosaic of different ecosystems associated with the Andes; it represents a wide range of biological and physical variations that also form the basis for its rich cultural diversity. Unsustainable practices of land and natural resources use and weak environmental and management administration threaten this megadiversity. In this context, the Peru-Finland Biological Diversity of the Peruvian Amazon project (BIODAMAZ) was initiated. It is a cooperation project between the governments of Peru and Finland (Phase I 1999-2002, Phase II 2003-2007). The BIODAMAZ

1 Proyecto Diversidad Biológica de la Amazonía Peruana - BIODAMAZ, Perú - Finlandia. Av. Abelardo Quiñones km 2.5, Iquitos, Perú / Instituto de Investigaciones de la Amazonía Peruana - IIAP, Av. Abelardo Quiñones km 2.5, Iquitos, Perú. Correo electrónico: dnbiodamaz@iiap.org.pe / biodamaz@iiap.org.pe

2 Proyecto Diversidad Biológica de la Amazonía Peruana - BIODAMAZ, Perú - Finlandia. Av. Abelardo Quiñones km 2.5, Iquitos, Perú / Biota BD Oy, Tykistökatu 6 B, 20520 Turku, Finlandia / Departamento de Biología, Universidad de Turku, 20014 Turku, Finlandia. Correo electrónico: biodamaz@iiap.org.pe
} 
project has contributed significantly to the conservation and sustainable use of biological diversity, through the development of administrative and management tools and research methodologies for biological diversity, achieving the following results: strengthening of environmental management and administration; improving access to international funding sources for conservation and sustainable use of biological diversity; strengthening of ability for international negotiation of Peruvian environmental authorities; improvement of systematization, organization and access to information on biological diversity; strengthening the process of the regional land use planning tool, the Ecological Economic Zoning; enhancement of knowledge on distribution patterns of Amazonian biological diversity for land use planning; strengthening of local, regional and national capacities; and strengthening of inter-institutional collaboration.

Key words: administrative and managerial tools, biological diversity, conservation, Peruvian Amazon, PeruvianFinnish cooperation, project BIODAMAZ, research methodologies, sustainable use.

\section{INTRODUCCIÓN}

Después de la Cumbre de las Naciones Unidas para el Desarrollo y el Medio Ambiente ("Cumbre para la Tierra”, 1992) en Río de Janeiro, Brasil, numerosos proyectos de cooperación internacional y programas nacionales han sido desarrollados y realizados para responder a los retos planteados en el Convenio sobre la Diversidad Biológica (CDB) suscrito en dicha cumbre. Una búsqueda rápida resultó positiva en casi 700 proyectos de la base de datos del Fondo para el Medio Ambiente Mundial (FMAM), sobre proyectos en el área focal de la diversidad biológica (www.gefonline.org). El FMAM sirve como el mecanismo de financiamiento para cuatro convenciones ambientales internacionales, entre ellas, el CDB. En los compromisos nacionales e internacionales la meta es cumplir con los objetivos del CDB, que son: 1) la conservación de la diversidad biológica, 2) la utilización sostenible de sus componentes, y 3) la participación justa y equitativa en los beneficios que se deriven de la utilización de los recursos genéticos (CDB, 1992).

El CDB compromete a los países desarrollados, que son Partes Contratantes del CDB, a proporcionar recursos financieros nuevos a las Partes Contratantes, que son países en desarrollo. El cumplimiento de este compromiso, según el CDB, puede ser alcanzado a través de recursos financieros relacionados con la aplicación del CBD por conducto de canales bilaterales, regionales y multilaterales. Para cumplimiento del compromiso ante el CDB, las repúblicas del Perú y Finlandia, como Partes Contratantes, iniciaron un proyecto bilateral de cooperación técnica en 1999. Dicho proyecto fue resultado de una propuesta del Gobierno del Perú al Gobierno de Finlandia, en 1995, de establecer un proyecto de cooperación técnica para evaluar la diversidad biológica de la Amazonía peruana y apoyar al país en la elaboración de una estrategia para la conservación y el uso sostenible de la diversidad biológica de la región amazónica. Esta propuesta se basó en una cooperación científica de 20 años entre el Perú y Finlandia, ejecutada mayormente por la Universidad de Turku de Finlandia y por instituciones peruanas, tales como el Instituto Nacional de Recursos Naturales (INRENA), la Universidad Nacional Mayor de San Marcos (UNMSM), la Universidad Nacional de la Amazonía Peruana (UNAP), y la Universidad Nacional Agraria La Molina (UNALM), entre otras organizaciones.

El proyecto Diversidad Biológica de la Amazonía Peruana, Perú - Finlandia (BIODAMAZ), fue fruto del acuerdo de ambos gobiernos. Éste se ejecutó a través de dos convenios: el primero, firmado el 29 de septiembre de 1999, para Componentes 1 y 2; y el segundo, para Componente 3, suscrito el 17 de enero del 2001. El proyecto tuvo un plazo de ejecución de tres años que se cumplió el 30 de septiembre del 2002 para los Componentes 1 y 2, y para el Componente 3, el 31 de diciembre de 2002. A partir del año 2003 se ejecutará la Fase II del proyecto BIODAMAZ (2003 - 2007). El proyecto tiene como contraparte nacional al Instituto de Investigaciones de la Amazonía Peruana (IIAP), y como contraparte finlandesa a un consorcio formado por la empresa finlandesa de consultorías ambientales, Biota BD Oy, y la Universidad de Turku (UTU).

En este artículo nosotros resumimos los avances más importantes logrados por el proyecto BIODAMAZ, Perú -Finlandia, evaluamos la importancia e impacto de estos avances, y presentamos algunas lecciones aprendidas durante la ejecución del proyecto. 


\section{ANTECEDENTES}

La crisis ecológica es un proceso mundial y globalizado que ha dado lugar a una intensa discusión de los problemas ambientales al nivel internacional, dado el deterioro irreversible que está sufriendo el planeta, inclusive en áreas remotas como la Amazonía peruana. La pérdida de especies y hábitats, y los cambios en los ecosistemas, sumados al cambio climático, la destrucción acelerada de los bosques, la erosión y pérdida de los suelos, los altos niveles de contaminación de las aguas y del aire, y la pérdida de los conocimientos y culturas indígenas, así como los altos niveles de pobreza de los países que cuentan con la mayor diversidad biológica, han impulsado una serie de acuerdos y compromisos compartidos entre los países, tales como el CDB y la Convención Marco de Naciones Unidas sobre Cambio Climático, entre otros, para reducir y mitigar éstos y otros riesgos ambientales, proteger los derechos de las comunidades tradicionales e indígenas, y conservar la flora y fauna, los ecosistemas y los genes. (UNEP, 1995).

El Perú ha sido tipificado como país clave para la conservación del ambiente y de la diversidad biológica, según el Informe "Una Evaluación de la situación de los Bosques Cerrados, Remanentes en el Mundo" del Programa de las Naciones Unidas para el Medio Ambiente (PNUMA, 2002). Así mismo, se caracteriza al Perú entre los 15 países claves del mundo y como uno de los que tiene mejores perspectivas debido a la baja presión de la población sobre los bosques, en comparación con países como la India o China, donde la presión es significativamente más alta (PNUMA, 2002). Adicionalmente, el Perú es considerado como un país megadiverso por estar entre los diez países más ricos en diversidad biológica del mundo (ENDB, 2001). Reconociendo esta realidad, el Perú ha suscrito tratados internacionales con el objeto de fortalecer la capacidad de conservación de este patrimonio. Así mismo, viene orientando políticas nacionales para conservar y aprovechar sosteniblemente este capital natural, con el propósito de incrementar su contribución a la producción nacional como estrategia clave para disminuir los altos índices de pobreza y desempleo.

La Amazonía peruana, particularmente la selva baja, es un mosaico de ecosistemas asociados a la cordillera de los Andes, en la cual nacen los ríos que alimentan al río Amazonas. La Amazonía presenta una gama de ecosistemas con variaciones biofísicas y ambientales relacionadas entre sí, que son la causa y origen de una alta diversidad biológica. También se caracteriza por un alto índice de endemismo y un potencial incalculable de recursos genéticos, que al mismo tiempo son la base de su alta diversidad cultural. (Kalliola et al., 1993, Kalliola y Flores Paitán, 1998). En su mayor parte la diversidad biológica amazónica es aún desconocida: esto se debe a su gran diversidad, a la falta de estudios, y a la inaccesibilidad de muchos lugares amazónicos. Este panorama dificulta la planificación del uso sostenible de los recursos naturales, que es el fundamento para el desarrollo sostenible en la Amazonía peruana, donde la población todavía depende directamente de los recursos de la diversidad biológica para su subsistencia y para comercialización en los mercados locales.

El problema actual en la Amazonía peruana es la degradación y pérdida progresiva de la diversidad biológica; ésta a su vez genera diversos impactos ambientales, sociales y económicos, como la alteración de los procesos ecológicos esenciales que son el sustento de los bienes y servicios de los recursos naturales renovables; la disminución o pérdida del potencial alimenticio, medicinal y de servicios ambientales; el empobrecimiento cultural; y la reducción de la capacidad productiva de los ecosistemas. La pérdida de la diversidad biológica tiene varias causas: la falta de integración y coordinación de las diversas instituciones nacionales y regionales amazónicas que trabajan en temas relacionados a la diversidad biológica; una débil gestión ambiental debido a la falta de recursos humanos e instrumentos apropiados y convincentes; y la falta de mejor entendimiento y conocimiento sobre los recursos naturales y de las técnicas para su uso adecuado.

El uso inadecuado de los recursos naturales es propiciado fundamentalmente por lo siguiente:

- $\quad$ Los cambios de uso de la tierra;

- La sobreexplotación;

- $\quad$ El predominio de prácticas extractivas no sostenibles y con alto porcentaje de desperdicio;

- El uso de tecnologías inadecuadas y la escasa oferta de tecnologías apropiadas;

- El incipiente desarrollo y la carencia de conocimiento estratégico de mercados para productos de la diversidad biológica;

- La existencia de políticas públicas que propician el uso no sostenible y la falta de políticas promotoras; 
- El bajo nivel de capacidades humanas; y

- El bajo nivel de conciencia y valoración de los recursos naturales.

Las causas están generadas a su vez, por la carencia de una política ambiental a largo plazo, incoherencia normativa transectorial, débil participación de la sociedad civil, carencia de herramientas de gestión ambiental y de conservación y uso sostenible de la diversidad biológica, centralismo en las decisiones sobre la gestión de los recursos naturales, bajo nivel de capacidades humanas, y existencia de una información dispersa y de acceso restringido.

En este contexto surgió el proyecto BIODAMAZ, Perú - Finlandia, que pretendió jerarquizar los intereses y las propuestas de los diversos actores, y focalizar su intervención en la atención de las estrategias que favorecen la ampliación del conocimiento, el soporte técnico para el desarrollo de instrumentos de gestión para la conservación y uso sostenible de la diversidad biológica, y la gestión ambiental, el mejoramiento de capacidades humanas regionales, y en el fortalecimiento de la interinstitucionalidad y la participación regional. El objetivo general del proyecto BIODAMAZ, en la Fase I, fue la conservación y uso sostenible de la diversidad biológica amazónica. Su propósito fue brindar metodologías de trabajo -instrumentos de gestión y metodologías de investigación-, para el manejo sostenible de la diversidad biológica de la Amazonía peruana. A través de estas acciones, el proyecto aspiró, en última instancia, a asistir el desarrollo socioeconómico sostenible de la Amazonía peruana.

\section{AVANCES EN EL DESARROLLO DE INSTRUMENTOS DE GESTIÓN PARA LA CONSERVACIÓN Y USO SOSTENIBLE DE LA DIVERSIDAD BIOLÓGICA AMAZÓNICA}

El proceso de elaboración de la Estrategia Nacional sobre la Diversidad Biológica del Perú (ENDB) se concluyó en el año 2001 a través de su aprobación por el Decreto Supremo No 102-2001-PCM y su subsiguiente publicación (ENDB, 2001), cumpliendo así uno de los requisitos del CDB sobre planificación estratégica de la conservación y uso sostenible de la diversidad biológica que cada Parte Contratante está obligada a llevar a cabo (Artículo 6 del CDB). La ENDB incluye la Estrategia Regional de la Diversidad Biológica Amazónica (ERDBA), cuya finalización se realizó con el apoyo del proyecto BIODAMAZ. La ERDBA fue compilada por organizaciones e instituciones peruanas que administran, gestionan, manejan, planifican y usan la diversidad biológica de la Amazonía peruana. La ERDBA es un instrumento de planificación cuyo objetivo es establecer prioridades y adoptar acciones y medidas de política para una adecuada conservación y uso sostenible de la diversidad biológica. La ERDBA orienta políticas para alcanzar en los próximos 20 años la conservación y uso sostenible de la diversidad biológica amazónica, favoreciendo la toma de decisiones con especial impacto en el mantenimiento del potencial del capital natural, biológico y cultural, la promoción de la inversión y el empleo, y el acceso de las poblaciones locales a los beneficios derivados de la diversidad biológica. El documento de la estrategia ha sido publicado (BIODAMAZ, 2001a), y ésta viene siendo difundida y promovida con el propósito de viabilizar su sostenibilidad.

Como una parte integral de la ERDBA están los planes de acción (BIODAMAZ, 2004f), que el proyecto BIODAMAZ ayudó a desarrollar durante el proceso de elaboración de la ERDBA. Los planes de acción especifican más a fondo los pasos necesarios para la implementación de la estrategia, desarrollando aspectos prácticos. Los planes de acción están organizados para desarrollar proyectos y actividades en forma integral en la Amazonía peruana, pero se desarrolló también planes de acción para los cuatro departamentos del área del proyecto: Loreto, Ucayali, San Martín y Madre de Dios, a fin de afrontar las particularidades departamentales.

Los planes de acción operan conjuntamente con la ERDBA y contribuirán sin duda a la gestión descentralizada de la conservación y uso sostenible de la diversidad biológica al nivel nacional y en la Amazonía peruana, y facilitarán el acceso al financiamiento y la cooperación nacional e internacional en los proyectos y actividades priorizados.

Como parte de los planes de acción de la ERDBA, una propuesta de un plan de acción departamental de conservación in situ y ex situ para el departamento de Loreto (BIODAMAZ, 2004e), fue elaborada conjuntamente 
con especialistas de diferentes instituciones públicas y privadas loretanas. La propuesta está referida al departamento de Loreto, que representa la tercera parte del territorio nacional y es el espacio con menor alteración de su diversidad biológica, forma parte de la selva baja, y contiene áreas de singular importancia para la conservación por su diversidad biológica. Se ha considerado indispensable integrar estrategias de conservación in situ y ex situ para garantizar mejor la integridad de conservación y aprovechamiento sostenible de la diversidad biológica en el departamento de Loreto. El plan desarrolla el marco conceptual de la conservación in situ y ex situ y el marco estratégico que contiene la visión, misión, objetivos estratégicos; a partir de los cuales se propone un conjunto de acciones y proyectos.

Adicionalmente a estos documentos, fueron elaborados tres documentos relacionados con el plan de acción de conservación in situ y ex situ de Loreto, para detallar y especificar las acciones de conservación y uso sostenible de la diversidad biológica en las áreas cercanas de la ciudad de Iquitos, que tienen una diversidad biológica excepcional y una fuerte presión humana de utilización (Kalliola y Flores Paitán, 1998). El proyecto BIODAMAZ colaboró con la Facultad de Ingeniería Forestal (FIF) de la UNAP para elaborar un plan de desarrollo del Jardín Botánico - Arboretum El Huayo (JBAH) (BIODAMAZ, 2004g). El JBAH es un área para la conservación in situ y ex situ de la diversidad biológica que conserva una muestra de bosques naturales representativos de las comunidades vegetales de la cuenca baja del río Nanay, y plantaciones de especies forestales y plantas menores de diferentes usos. El plan define una visión de futuro para el JBAH, objetivos estratégicos y un conjunto de estrategias, acciones y proyectos para alcanzar los objetivos. El plan incluye también estudios de uso turístico y de educación ambiental, así como un mapa con la propuesta de zonificación del área lo que favorecerá la integración de la conservación y uso sostenible con las comunidades aledañas al JBAH.

Como aporte al proceso de elaboración del plan maestro de la Zona Reservada Allpahuayo-Mishana (ZRAM), el proyecto BIODAMAZ compiló un documento sobre las bases biofísicas de la ZRAM, incluyendo también propuestas de zonificación y de programas para el plan maestro (BIODAMAZ, 2004a). La ZRAM es un área importante para la conservación de la diversidad biológica en las cercanías de la ciudad de Iquitos, porque es un mosaico de diferentes ecosistemas con variaciones ambientales muy marcadas, que influyen en su alta riqueza de especies de plantas y animales. La Zona Reservada presenta también la concentración más extensa de bosques sobre arena blanca conocida en el Perú, y alberga muchas especies de flora y fauna endémicas, únicas y de distribución restringida. Su protección es de mucha importancia y urgencia por la presión que sufre por el uso no sostenible de los recursos encontrados allá, incrementada por su cercanía al mercado más grande de la Amazonía peruana, el de la ciudad de Iquitos (Álvarez et al., 2004). Como una de las alternativas de aprovechamiento sostenible de la diversidad biológica en la zona fue elaborada por el proyecto BIODAMAZ una propuesta para un plan de desarrollo turístico en el eje de la carretera Iquitos-Nauta (BIODAMAZ, 2004h).

Una parte fundamental de la gestión y manejo de la diversidad biológica es el manejo de la información sobre la misma. Un sistema de información se ve como un conjunto de información localizada en diferentes instituciones que organizan, manejan y mantienen su información sobre la diversidad biológica amazónica, y que están vinculadas entre sí, vía diversos mecanismos de comunicación. Se actúa como una red coordinadora de información, que buscará sistematizar los esfuerzos científicos y técnicos institucionales, y personales al nivel regional, nacional e internacional. Permite coordinar un lenguaje para el levantamiento y ordenamiento de la información, incluyendo su incorporación inmediata al acervo científico y técnico, evitando así la dispersión y vacío de información en el estado del arte del conocimiento sobre la diversidad biológica y el ambiente amazónico. Según estas ideas, el proyecto BIODAMAZ, conjuntamente con instituciones públicas y privadas amazónicas y nacionales, elaboró el Sistema de Información de la Diversidad Biológica y Ambiental de la Amazonía Peruana - SIAMAZONIA (BIODAMAZ, 2001b; Miyakawa et al., 2002). Actualmente, el SIAMAZONIA está operando y prestando servicios a los distintos actores de la conservación y uso sostenible de la diversidad biológica en Internet (www.siamazonia.org.pe). Sistemas de información relacionados desarrollados por el proyecto BIODAMAZ son: Sistema de Información del Jardín Botánico - Arboretum El Huayo, desarrollado en colaboración con la FIF de la UNAP (SIHUAYO; www.siamazonia.org.pe), Sistema de Información de la Zona Reservada Allpahuayo - Mishana desarrollado en colaboración con la Facultad de Ingeniería de Sistemas (FISI) de la UNAP (SIZRAM; www.siamazonia.org.pe), y el Sistema de Información Turística Iquitos - Río Amazonas desarrollado en colaboración con actores relacionados al sector turismo, en Iquitos y Loreto (SITURISMO; www.siturismo.org.pe). 


\section{AVANCES EN EL CONOCIMIENTO DE LA DIVERSIDAD BIOLÓGICA DE LA AMAZONÍA PERUANA}

El primer mosaico de imágenes de satélite (Landsat TM) de 42 escenas que cubre toda la Amazonía baja peruana fue elaborado por el proyecto BIODAMAZ (Bendayán et al., 2002; BIODAMAZ, 2004c). Por primera vez, es posible apreciar a simple vista todo el panorama de la Amazonía peruana y la gran diversidad ambiental presente dentro de la región. El mosaico es una herramienta fundamental en estudios biogeográficos de la diversidad biológica, puede ayudar a ubicar sitios interesantes en la Amazonía peruana que pudieran albergar patrones de diversidad biológica desconocidos hasta ahora e importantes para la conservación. El mosaico no es sólo útil en estudios básicos, sino que también tiene una aplicabilidad práctica en la planificación del uso de la tierra, como fuente de información básica para el proceso de Zonificación Ecológica Económica (ZEE), que sirve como herramienta para el ordenamiento territorial. El mosaico elaborado sirvió como insumo fundamental para elaborar un mapa de diversidad de vegetación que muestra la gran diversidad de tipos de vegetación encontrados en la Amazonía peruana, y un mapa de macrounidades ambientales que presenta áreas relativamente homogéneas según sus caracteres biofísicos. Para la elaboración del mapa de macrounidades ambientales se profundizó la metodología utilizada para aumentar la rigurosidad científica del método de la ZEE (BIODAMAZ, 2004d). El mosaico y los mapas están libremente disponibles para el público en Internet a través del SIAMAZONIA, los que podrán ser mejorados a través del intercambio técnico-científico.

Fueron realizados también estudios de campo para ayudar en la verificación de los patrones observados en las imágenes de satélite, en el proceso de elaboración de los mapas de diversidad de vegetación y de marcounidades ambientales. Los estudios contemplaron tres grupos de plantas (helechos terrestres, palmeras y plantas de la familia Melastomataceae) y tres grupos de animales (aves, anfibios anuros de las familias Dentrobatidae, Hylidae y Leptodactylidae, y hormigas de la tribu Dacetini), en trece localidades ubicadas en la selva baja peruana del norte, centro y sur (Rodríguez et al., 2002). Los estudios fueron realizados y los resultados analizados utilizando métodos estandarizados, anteriormente usados en trabajos semejantes (BIODAMAZ, 2004b). A través de estos estudios se pretendió validar una metodología que permitiera encontrar algunos grupos de plantas y animales asociados con ciertas características físicas y biológicas (tipo de suelo o clima, o tipo de formación vegetal) del medio ambiente, y que explicara ciertos patrones de diversidad biológica. Los resultados indican que los grupos de plantas estudiados pueden servir como indicadores de los patrones de distribución de otros grupos de plantas (por ejemplo, árboles), pero no parecen servir como indicadores de patrones de distribución de las especies de animales estudiadas. También se encontró que una parte significativa de la variación florística puede ser observada en las imágenes de satélite, lo que significa que los métodos de percepción remota son útiles para la evaluación de patrones de distribución de diversidad biológica en la Amazonía peruana. (Rodríguez et al., 2002).

El proyecto BIODAMAZ llevó a cabo además otros estudios de campo en el JBAH y en la ZRAM. En el JBAH fue realizado un inventario del Arboretum para identificar especies de árboles dentro del área y estudiar la importancia económica y ecológica de las plantas del JBAH (Valderrama, 2002). En la ZRAM fueron ejecutados tres proyectos de investigación para proporcionar información para el proceso de elaboración del plan maestro; éstos fueron: un inventario de los animales de caza, clasificación de los bosques sobre arena blanca, y mapeo de las trochas existentes.

El inventario de fauna mostró que hay ciertas áreas en la Zona Reservada Allapahuayo - Mishana que están bajo intensa presión de caza por los pobladores locales y por cazadores de afuera de la ZRAM. Sin embargo, aun así existen áreas con buena presencia de especies mayores de caza y también de especies raras que necesitan ser protegidas. (Oversluijs, 2002). Estos estudios son muy importantes en la zonificación de la ZRAM en zonas de protección y de uso. En el estudio de clasificación de los bosques sobre arena blanca (conocidos localmente como varillales) por primera vez se pudo, tentativamente, clasificar cualitativa y cuantitativamente los varillales en cinco clases (García et al., 2002), y estudiar la preferencia de algunas plantas por diferentes tipos de varillales (Ahuite et al., 2002). Esta información es muy útil para entender el funcionamiento del área y comprobar la existencia en la ZRAM de un mosaico único de diferentes tipos de bosques en cercanía próxima entre sí. El mapeo de las trochas en la ZRAM muestra por primera vez la red de trochas existentes dentro de la Zona Reservada; esta información será útil en la zonificación y planificación de la ZRAM (ver SIAMAZONIA). 
Debido a la gran demanda de información actualizada sobre el área de influencia de la carretera Iquitos-Nauta, y sobre la presión ejercida sobre los recursos biológicos, combinada con la ocupación desordenada de la tierra, que ponen en peligro su existencia, se decidió compilar el conocimiento biofísico y socioeconómico actual en un libro para hacer llegar este conocimiento a un público amplio, incluyendo a los tomadores de decisiones, quienes tienen que llegar a conclusiones en cuanto al futuro de la zona de Iquitos y sus alrededores. El libro "Camino al desarrollo sostenible: Bases técnicas y científicas de desarrollo sostenible de la zona Iquitos - Nauta en la Amazonía del Perú" (BIODAMAZ / STD3 / IIAP, 2004), es una sinopsis de conocimientos científicos y prácticos, relacionados con la zona de Iquitos, que reflejan la situación en el cambio del milenio. Para que el desarrollo sea sostenible se necesita una base de conocimiento del ambiente en la región y de las opciones y limitaciones presentes. Esta publicación fue elaborada para contribuir a esta necesidad con información analizada, sintetizada y actualizada.

El desarrollo da cada uno de los resultados anteriores, tanto en la gestión de la diversidad biológica como en la generación de conocimientos sobre ella, trajo consigo eventos de fortalecimiento de capacidades, lo que el proyecto BIODAMAZ enfatizó durante toda su ejecución. Fueron de especial significado el fortalecimiento de capacidades en formulación de marcos conceptuales, diseño y puesta en servicio de sistemas de información integrados a servidores de mapas, elaboración de mosaicos de imágenes de satélite para macro espacios, bases científicas y técnicas de la diversidad de vegetación, macrounidades ambientales y su integración a la metodología de Zonificación Ecológica Económica, metodologías de identificación de patrones de diversidad biológica, utilizando indicadores de flora y fauna, marco conceptual de conservación in situ y ex situ, y planificación de la conservación y uso sostenible de la diversidad biológica. Igualmente importante para el proyecto fue el fortalecimiento de la articulación e integración institucional, entre instituciones y organizaciones peruanas dentro del sector ambiental y entre sectores de la sociedad.

\section{IMPACTOS DEL PROYECTO BIODAMAZ}

Se proyecta que a través de los resultados anteriormente expuestos, el proyecto genere impactos a largo plazo, cuya influencia se extienda más allá de la vida del propio proyecto. Se han considerado los siguientes impactos del proyecto (BIODAMAZ, 2002):

- Mejoramiento de la conciencia ambiental debido a la capacitación, ampliación del conocimiento, y el funcionamiento de los sistemas de información de la diversidad biológica;

- Ampliación de la base de información sobre la diversidad biológica de la Amazonía peruana, desarrollo de metodologías útiles para el análisis de la diversidad biológica, y apoyo al desarrollo de políticas y a la planificación del uso de la tierra;

- Fortalecimiento de la descentralización, la institucionalidad, y las relaciones intersectoriales e interinstitucionales, por ampliación del conocimiento para la toma de decisiones sobre la diversidad biológica, por contar con instrumentos de gestión, tales como planes, estrategias, y sistemas de información en diversidad biológica, y por el fortalecimiento de las capacidades locales y regionales;

- Enriquecimiento de la cultura ambiental de los diversos actores sociales para el cuidado y valoración de la diversidad biológica, sobre la base de nuevos conocimientos y sistemas de información útiles y accesibles;

- Mejoramiento de la situación de la conservación in situ y ex situ en la zona de Iquitos, por ampliación de conocimiento y capacitación, y la disponibilidad de instrumentos de gestión especializados en el tema.

\section{LECCIONES APRENDIDAS DURANTE LA EJECUCIÓN DEL PROYECTO BIODAMAZ}

El proceso para lograr los resultados del proyecto ha permitido no solo reconocer la fructífera cooperación finlandesa - peruana, sino también confirmar, renovar e identificar un conjunto de enseñanzas que consideramos serán de utilidad para futuras experiencia de investigación y desarrollo en la Amazonía peruana (BIODAMAZ, 2002): 
- El marco conceptual del desarrollo sostenible de la Amazonía Peruana va más allá del tradicional triángulo del desarrollo sostenible de tres dimensiones -económico, social y ambiental-, al requerir la incorporación de una cuarta dimensión expresada en lo político-institucional, constituyéndose así el diamante del desarrollo sostenible de la Amazonía peruana.

- Manejar información a través de sistemas de información accesibles a los tomadores de decisiones políticas y de inversión, es clave para la gestión eficiente de la investigación y del desarrollo.

- Usar metodologías y tecnología contemporánea, como por ejemplo indicadores de diversidad biológica y la teledetección, facilita sustancialmente la ampliación del conocimiento sobre patrones de la diversidad biológica, particularmente en espacios tan complejos y extensos como la Amazonía peruana.

- Existe la necesidad de continuar fortaleciendo las capacidades y la rigurosidad científica en la región para impulsar la conservación, el uso sostenible y la cultura de valoración de la diversidad biológica para el desarrollo amazónico.

- La necesidad de explorar soluciones para la conservación y uso sostenible de la diversidad biológica más allá de los medios y los problemas inmediatos, y plantearse un ideal, precisar lo que se quiere y desarrollar nuevos paradigmas y actitudes para el cambio, son aspectos claves para el desarrollo.

- El conocimiento científico integrado al conocimiento tradicional es consustancial al desarrollo sostenible.

- La integración de la multidisciplinariedad y la interinstitucionalidad en el diseño, ejecución y difusión de resultados constituyen las bases fundamentales para el logro de resultados útiles y sostenibles.

- Los resultados son más sostenibles y útiles cuando son integrados a la agenda institucional de las instituciones y organizaciones involucradas en la ejecución del proyecto.

- La descentralización de las capacidades y oportunidades es viable y genera nuevas y mejores oportunidades para el país.

- La integración amplia y de mutua confianza entre los equipos peruanos y finlandeses ha enriquecido enfoques y visiones, fortaleciendo una fructífera cooperación.

- Existe la necesidad de fortalecer las técnicas de planificación en las distintas especialidades profesionales, principalmente en las disciplinas biofísicas.

\section{CONCLUSIONES}

El gobierno peruano, entre sus prioridades de desarrollo, orienta políticas encaminadas al aprovechamiento sostenible de los bosques amazónicos, particularmente de los recursos forestales madereros, el turismo sostenible y otros recursos y servicios de la diversidad biológica amazónica, decisiones que requieren estar sustentadas en sólidos conocimientos con bases técnicas y científicas, para garantizar impactos socioeconómicos y ambientales favorables.

Así mismo, el proyecto BIODAMAZ, como resultado de una significativa cooperación entre los gobiernos de Perú y de Finlandia, ha iniciado y fortalecido algunos procesos para ampliar el conocimiento y fortalecer la gestión de la conservación y uso sostenible de la diversidad biológica. Los resultados del proyecto BIODAMAZ son un aporte significativo a la conservación y uso sostenible de la diversidad biológica de la Amazonía peruana. Los avances en la conservación de la diversidad biológica y una evaluación de su importancia e impactos están presentados en forma resumida en la Tabla 1.

Sin embargo, es importante aprender de esta experiencia y reforzar la sostenibilidad de los resultados a través del fortalecimiento de los procesos iniciados y la implementación de las herramientas de gestión y manejo desarrolladas. El apoyo para esto será una de las tareas de la Fase II del proyecto BIODAMAZ, Perú - Finlandia.

La aplicación práctica de estos resultados, abriendo espacios a la participación e integrando enfoques de conservación y desarrollo, contribuirá sin duda a la práctica de la democracia y al fortalecimiento de la 
descentralización en el Perú, así como a la ampliación de oportunidades de inversión y de empleo, generando impactos positivos en la disminución de la pobreza, aspectos que son prioridades manifiestas en las políticas de la cooperación de Finlandia, y renovada aspiración de la sociedad peruana.

\section{AGRADECIMIENTOS}

Nuestro agradecimiento más profundo a todos nuestros colegas del proyecto BIODAMAZ por su trabajo extraordinario en el logro de los resultados del proyecto; a las instituciones ejecutoras, el IIAP, Biota BD Oy, y la UTU, y a su personal, por el apoyo en la implementación del proyecto. Finalmente, a los gobiernos del Perú y de Finlandia, y a sus representantes en ambos países, por la oportunidad brindada para llevar a cabo este proyecto.

\section{BIBLIOGRAFÍA}

AHUITE, M.; GARCÍA, R.; RUOKOLAINEN, K. 2002. Preferencia de cuatro especies de plantas al drenaje y la altura en los bosques sobre arena blanca en la Zona Reservada Allpahuayo-Mishana. Folia Amazónica 14 (1-2): 149-157 pp.

ÁLVAREZ, J.; JUVONEN, S.-K.; SOINI, P. 2004. Retos de conservación en un área diversa y compleja. En: BIODAMAZ; STD3; IIAP. Camino al desarrollo sostenible: Bases técnicas y científicas para el desarrollo sostenible de la zona Iquitos-Nauta en la Amazonía del Perú. BIODAMAZ, Perú-Finlandia. Iquitos, Perú.

BENDAYÁN, L.; SANJURJO, J.; KALLIOLA, R.; RODRÍGUEZ, F. 2002. Experiencia de la tecnología de percepción remota para la elaboración del mosaico de imágenes de satélite Landsat TM en la selva baja de la Amazonía peruana. Folia Amazónica 14 (1-2): 73-86 pp.

BIODAMAZ. 2001a. Estrategia Regional de la Diversidad Biológica Amazónica. Documento Técnico No 01. Serie BIODAMAZ-IIAP. Iquitos, Perú.

BIODAMAZ. 2001b. Sistema de Información de la Diversidad Biológica y Ambiental de la Amazonía Peruana. Documento Técnico No 02. Serie BIODAMAZ-IIAP. Iquitos, Perú.

BIODAMAZ. 2002. Aportes al conocimiento y a la gestión de la diversidad biológica de la Amazonía peruana. Informe Final 1992-2002. BIODAMAZ, Perú - Finlandia. Iquitos, Perú.

BIODAMAZ. 2004a. Bases biofísicas y propuestas de zonificación y de programas para el plan maestro de la Zona Reservada Allpahuayo - Mishana. Documento Técnico No 10. Serie BIODAMAZ-IIAP. Iquitos, Perú.

BIODAMAZ. 2004b. Guía para estudiar patrones de distribución de especies amazónicas. Documento Técnico No 06. Serie BIODAMAZ-IIAP. Iquitos, Perú.

BIODAMAZ. 2004c. Manual para la elaboración de mosaicos de imágenes de satélite Landsat TM para la selva baja peruana. Documento Técnico No 03. Serie BIODAMAZ-IIAP. Iquitos, Perú.

BIODAMAZ. 2004d. Marco teórico y metodológico para identificar unidades ambientales en la selva baja peruana. Documento Técnico No 05. Serie BIODAMAZ-IIAP. Iquitos, Perú.

BIODAMAZ. 2004e. Plan de acción de conservación in situ y ex situ de la región Loreto. Documento Técnico No 08. Serie BIODAMAZ-IIAP. Iquitos, Perú.

BIODAMAZ. 2004f. Plan de acción de la Estrategia Regional de la Diversidad Biológica Amazónica. Documento Técnico No 04. Serie BIODAMAZ-IIAP. Iquitos, Perú. 
BIODAMAZ. 2004g. Plan de desarrollo del Jardín Botánico-Arboretum El Huayo. Documento Técnico No 09. Serie BIODAMAZ-IIAP. Iquitos, Perú.

BIODAMAZ. 2004h. Plan estratégico de desarrollo turístico en la carretera Iquitos-Nauta: Atractivos turísticos y lineamientos de uso. Documento Técnico No 11. Serie BIODAMAZ-IIAP. Iquitos, Perú.

BIODAMAZ / STD3 / IIAP. 2004. Camino al desarrollo sostenible: Bases técnicas y científicas para el desarrollo sostenible de la zona Iquitos-Nauta en la Amazonía del Perú. BIODAMAZ, Perú-Finlandia. Iquitos, Perú.

CDB. 1992. Convenio sobre la Diversidad Biológica. www.biodiv.org/doc/legal/cbd-es.pdf.

ENDB. 2001. Perú: Estrategia Nacional sobre la Diversidad Biológica. Consejo Nacional del Ambiente (CONAM). Lima, Perú.

GARCÍA, R.; AHUITE, M.; OLÓRTEGUI, M. 2002. Clasificación de bosques sobre arena blanca de la Zona Reservada Allpahuayo - Mishana. Folia Amazónica 14 (1-2) : 17-26 pp.

KALLIOLA, R.; FLORES PAITÁN, S. (eds.). 1998. Geoecología y desarrollo amazónico: estudio integrado en la zona de Iquitos, Perú. Annales Universitatis Turkuensis Ser. A II 114. 544 pp.

KALLIOLA, R.; PUHAKKA, M.; DANJOY, W. (eds.). Amazonía Peruana. Vegetación húmeda tropical en el llano subandino. Proyecto Amazónica de la Universidad de Turku y Oficina Nacional de Evaluación de Recursos Naturales. Jyväskylä, Finlandia. 265 pp.

MIYAKAWA, V.; KALLIOLA, R.; MENA, J.L. Integración de información amazónica: Sistema de Información de la Diversidad Biológica y Ambiental de la Amazonía Peruana. Folia Amazónica 14 (1-2) : 87-98 pp.

OVERSLUIJS, M. 2002. Animales de caza en la Zona Reservada Allpahuayo - Mishana. Folia Amazónica 14 (1-2) : 7-16 pp.

PNUMA. 2002. Una Evaluación de la situación de los Bosques Cerrados, Remanentes en el Mundo. Programa de las Naciones Unidas para el Medio Ambiente.

RODRÍGUEZ, J.J.; CÁRDENAS, G.; CRUZ De La, A.; LLERENA, N.; RÍOS, S.; RIVERA, C.; SALAZAR, E.; VARGAS, V.H.; SOINI, P.; RUOKOLAINEN, K. 2002. Comparaciones florísticas y faunísticas entre diferentes lugares de bosques de tierra firme en la selva baja de la Amazonía peruana. Folia Amazónica 14 $(1-2): 35-72 \mathrm{pp}$.

SIAMAZONIA - Sistema de Información de la Diversidad Biológica y Ambiental de la Amazonía Peruana. www.siamazonia.org.pe.

UNEP. 1995. Heywood, V.H. (ed.). Global Biodiversity Assessment. United Nations Environmental Programme. University Press, Cambridge, Great Britain. 1140 pp.

VALDERRAMA, H. 2002. Especies de importancia económica y ecológica en el Jardín Botánico - Arboretum El Huayo, Iquitos, Perú. Folia Amazónica 14 (1-2) : 159-176 pp. 
Tabla 1. Avances importantes, su importancia e impactos a largo plazo en la conservación y uso sostenible de la diversidad biológica de la Amazonía peruana logrados por el proyecto BIODAMAZ, PerúFinlandia.

\begin{tabular}{|c|c|c|}
\hline Avances & Importancia & Impactos \\
\hline $\begin{array}{l}\text { Avances en las herramientas para } \\
\text { la gestión de la diversidad } \\
\text { biológica amazónica } \\
\text { Metodología para el diseño y } \\
\text { desarrollo de sistemas de informa- } \\
\text { ción para la conservación de la } \\
\text { diversidad biológica de la } \\
\text { Amazonía; } \\
\text { Metodología para el diseño y } \\
\text { consulta de instrumentos de } \\
\text { gestión para la conservación y uso } \\
\text { sostenible de la diversidad } \\
\text { biológica; } \\
\text { Validación y enriquecimiento de la } \\
\text { metodología para diseño, } \\
\text { monitoreo y evaluación de } \\
\text { proyectos de investigación y } \\
\text { desarrollo; } \\
\text { Estrategias y planes para la } \\
\text { conservación y uso sostenible de } \\
\text { la diversidad biológica. }\end{array}$ & $\begin{array}{l}\text { Fortalecimiento de la gestión } \\
\text { ambiental; } \\
\text { Posibilidad de acceder a las } \\
\text { fuentes de financiamiento del } \\
\text { Convenio sobre la Diversidad } \\
\text { Biológica; } \\
\text { Mejoras en la capacidad de } \\
\text { negociación; } \\
\text { Información sobre la diversidad } \\
\text { biológica amazónica más } \\
\text { accesible, sistematizada y } \\
\text { organizada. }\end{array}$ & $\begin{array}{l}\text { Mejoramiento de la conciencia ambiental } \\
\text { debido a la capacitación, la ampliación del } \\
\text { conocimiento, y el funcionamiento de los } \\
\text { sistemas de información de la diversidad } \\
\text { biológica; } \\
\text { Fortalecimiento de la descentralización; } \\
\text { Incremento de las oportunidades de la } \\
\text { asistencia técnica para la conservación y el } \\
\text { uso sostenible de la diversidad biológica } \\
\text { amazónica por el mejor entendimiento de } \\
\text { estos procesos; } \\
\text { Priorización de proyectos y acciones } \\
\text { necesarios, y cumplimiento de requisitos } \\
\text { de convenciones ambientales internaciona- } \\
\text { les, especialmente el Convenio sobre la } \\
\text { Diversidad Biológica; } \\
\text { Mejoramiento de la situación de la } \\
\text { conservación in situ y ex situ en la zona de } \\
\text { Iquitos, por ampliación de conocimiento, } \\
\text { capacitación e instrumentos de gestión } \\
\text { especializados en el tema; } \\
\text { Enriquecimiento del marco conceptual de } \\
\text { investigación de diversidad biológica, } \\
\text { conservación y desarrollo sostenible en la } \\
\text { Amazonía peruana. }\end{array}$ \\
\hline $\begin{array}{l}\text { Avances en el conocimiento sobre } \\
\text { la diversidad biológica amazónica } \\
\text { Metodología para la elaboración del } \\
\text { mosaico digitalizado de imágenes } \\
\text { de satélite para selva baja; } \\
\text { Metodología para la evaluación de } \\
\text { la diversidad de vegetación y para } \\
\text { la identificación de macro unidades } \\
\text { ambientales como parte fundamen- } \\
\text { tal para contribuir a la metodología } \\
\text { de la Zonificación Ecológica } \\
\text { Económica de la Amazonía } \\
\text { peruana; } \\
\text { Metodología para evaluar la } \\
\text { diversidad biológica, utilizando } \\
\text { especies indicadoras de flora y } \\
\text { fauna. }\end{array}$ & $\begin{array}{l}\text { Fortalecimiento del proceso de } \\
\text { la Zonificación Ecológica } \\
\text { Económica; } \\
\text { Nuevos conocimientos sobre } \\
\text { patrones de distribución de la } \\
\text { diversidad biológica } \\
\text { amazónica; } \\
\text { Nueva información para la } \\
\text { planificación del uso de la } \\
\text { tierra. }\end{array}$ & $\begin{array}{l}\text { Ampliación de la base de información } \\
\text { sobre la diversidad biológica de la } \\
\text { Amazonía peruana, desarrollo de } \\
\text { metodologías útiles para análisis de la } \\
\text { diversidad biológica, y apoyo al desarrollo } \\
\text { de políticas y a la planificación del uso de } \\
\text { la tierra; } \\
\text { Enriquecimiento de la cultura ambiental de } \\
\text { los diversos actores sociales de cuidado y } \\
\text { valoración de la diversidad biológica } \\
\text { basada en nuevos conocimientos y } \\
\text { sistemas de información útiles y accesi- } \\
\text { bles. }\end{array}$ \\
\hline
\end{tabular}




\begin{tabular}{|c|c|c|}
\hline Avances & Importancia & Impactos \\
\hline $\begin{array}{l}\text { Avances en el fortalecimiento de } \\
\text { capacidades y cooperación } \\
\text { interinstitucional } \\
\text { Fortalecimiento de capacidades en: } \\
\text { - marco conceptual, diseño y } \\
\text { puesta en servicio de sistemas de } \\
\text { información integrados a } \\
\text { servidores de mapas; } \\
\text { - elaboración de mosaicos de } \\
\text { imágenes de satélite para macro } \\
\text { espacios; } \\
\text { - bases científicas y técnicas de la } \\
\text { diversidad de vegetación, } \\
\text { macrounidades ambientales y su } \\
\text { integración a la metodología de } \\
\text { Zonificación Ecológica Económi- } \\
\text { ca; } \\
\text { - metodologías de identificación de } \\
\text { patrones de diversidad biológica, } \\
\text { utilizando indicadores de flora y } \\
\text { fauna; } \\
\text { - marco conceptual de conserva- } \\
\text { ción in situ y ex situ; } \\
\text { - planificación de la conservación y } \\
\text { uso sostenible de la diversidad } \\
\text { biológica; } \\
\text { Fortalecimiento de la articulación e } \\
\text { integración institucional entre } \\
\text { instituciones y organizaciones } \\
\text { peruanas dentro del sector ambien- } \\
\text { tal y entre sectores, a través de } \\
\text { consultas y discusiones regulares y } \\
\text { promoción de intercambio de } \\
\text { experiencias e información. }\end{array}$ & $\begin{array}{l}\text { Fortalecimiento de capacidades } \\
\text { regionales; } \\
\text { Fortalecimiento de articulación } \\
\text { interinstitucional. }\end{array}$ & $\begin{array}{l}\text { Fortalecimiento de la institucionalidad, y } \\
\text { las relaciones intersectoriales e } \\
\text { interinstitucionales, por ampliación del } \\
\text { conocimiento para la toma de decisiones } \\
\text { sobre la diversidad biológica, por contar } \\
\text { con instrumentos de gestión, tales como } \\
\text { estrategias, planes y sistemas de informa- } \\
\text { ción en diversidad biológica, y por el } \\
\text { fortalecimiento de las capacidades locales, } \\
\text { regionales y nacionales. }\end{array}$ \\
\hline
\end{tabular}

